L. Rakoczy ${ }^{1}$, M. Grudzień ${ }^{2}$, L. Tuz ${ }^{1}$, K. Pańcikiewicz ${ }^{1}$, A. Zielińska-Lipiec ${ }^{1}$

${ }^{1}$ AGH University of Science and Technology, Faculty of Metals Engineering and Industrial Computer Science, Al. Mickiewicza 30, 30-059 Cracow, Poland

${ }^{2}$ Foundry Research Institute, Zakopiańska 73, 30-418 Cracow, Poland

lrakoczy@agh.edu.pl

\title{
MICROSTRUCTURE AND PROPERTIES OF A REPAIR WELD IN A NICKEL BASED SUPERALLOY GAS TURBINE COMPONENT
}

\begin{abstract}
The aim of the present study was to characterize the repair weld of serviced (aged) solid-solution Ni-Cr-Fe-Mo alloy: Hastelloy X. The repair welding of a gas turbine part was carried out using Gas Tungsten Arc Welding (GTAW), the same process as for new parts. Light microscopy, scanning electron microscopy, transmission electron microscopy, microhardness measurements were the techniques used to determine the post repair condition of the alloy. Compared to the solution state, an increased amount of $\mathrm{M}_{6} \mathrm{C}$ carbide was detected, but $\mathrm{M}_{23} \mathrm{C}_{6}$ carbides, sigma and mu phases were not. The aged condition corresponds to higher hardness, but without brittle regions that could initiate cracking.
\end{abstract}

Keywords: long term service, gas turbine, superalloys, TEM, Hastelloy X

\section{INTRODUCTION}

Nickel based alloys are widely used for gas turbine parts withstand high homogeneous temperature, aggressive corrosion, different stress levels. Over the past 50 years, gas turbines have gained great importance in petroleum and power industry. Manufacturing of more and more complex structure makes the selection of materials the most important factor. Independently from the level of stress, temperature and corrosive environment, components must be reliable during service. Alloys that can meet above mentioned requirements are often high-priced materials and bring with them the use of advanced technologies during production of components [1]. Extending of service life and cost reduction are important both for the manufacturer and the customer. The solution is regeneration and repair rather than replacement. Development of repair technologies requires an individual approach to each component of gas turbine in order to ensure a sufficiently high quality. Repair conducted by welder or welding operator must be preceded by detailed identification of the part. Details about design, weldability, damage cause and requirements of standards and specifications must be known. The microstructure of the material after thousands of hours at a high temperature is changed, therefore the repair welding method may differ from that used during manufacture. Corrosive environment and high temperature can cause a gradual degradation of the microstructure, as cracks, wear and embrittlement [2,3]. Exposure to the operating temperature leads to the formation of secondary phases which have a significant effect on both strength and weldability. Nickel based alloys, due to their complex chemical 
composition, melt and solidify over a range of temperatures. This range is expanded with increasing amounts of alloying elements. Ni-Cr-Fe-Mo alloy known as Hastelloy X is usually supplied in solution heat treated condition, which guarantees very good weldability [4]. The important properties are also: excellent formability, high mechanical properties at elevated temperatures, and resistance to oxidation and stress corrosion. Additional chemical elements are chosen to ensure the aforementioned properties, as well as providing resistance to creep and brittle fracture [5,6]. According to Zhao [7], in addition to primary phases $\gamma$ and $\mathrm{M}_{6} \mathrm{C}$, topologically closed packed phases and $\mathrm{M}_{23} \mathrm{C}_{6}$ can also precipitate in the aged material. Clarke and Titus [8] reported that topologically closed packed phases in Hastelloy X are $\mu$ and $\sigma$. Formation of these phases can influence creation of low melting compounds. Appearing of low melting eutectic in the final stage of solidification of the welded joint may affect the tendency to hot cracking [9]. Knowledge of operating temperature and diagram timetemperature-transformation can help in proper planning of the repair process.

\section{EXPERIMENTAL PROCEDURE}

Hastelloy X repair welded joint was investigated. Welding was carried out by the Gas Tungsten Arc Welding process. Selection of parameters is presented in Table 1. Technique took into account sensitivity of nickel base alloys to overheating of weld pool and high density of molten nickel. The welding process was performed manually in position $2 \mathrm{~F}$ (horizontal position). Hastelloy $\mathrm{X}$ is solid solution strengthened alloy of composition given in Table 2. The base metal was provided after long term service as a part in an industrial gas turbine. To create the weld, a filler metal specified for Hastelloy X was used, according to AWS A5.14, marked as ERNICrMo-2 [10].

Table 1. Welding parameters

\begin{tabular}{|c|c|c|c|}
\hline Parameter & Current [A] & Voltage [V] & Travel speed [mm/min] \\
\hline Value & 55 & 12 & 200 \\
\hline
\end{tabular}

Table 2. Chemical composition of Hastelloy $X$

\begin{tabular}{|c|c|c|c|c|c|c|c|c|c|c|c|}
\hline Element & $\mathrm{Ni}$ & $\mathrm{Cr}$ & $\mathrm{Fe}$ & $\mathrm{Mo}$ & $\mathrm{Co}$ & $\mathrm{W}$ & $\mathrm{C}$ & $\mathrm{Mn}$ & $\mathrm{Si}$ & $\mathrm{Nb}$ & $\mathrm{Al}$ \\
\hline \% wt. & Balance & 20.38 & 14.8 & 9.22 & 1.39 & 0.76 & 0.05 & 0.42 & 0.5 & 0.36 & 0.12 \\
\hline
\end{tabular}

After weld repair an appropriate metallographic preparation preceded examination by light microscopy on Leica DM400. Sample was initially ground on sand papers and mechanically polished with a diamond coated disk. The final step was etching in Kalling's reagent. To reveal microstructural details, a Scanning Electron Microscope (SEM) investigation was conducted on an etched specimen using FEI Nova NanoSEM 450. Information about alloying element distribution in the weld was obtained using EDS attachment to SEM. For transmission electron microscopy (TEM) thin foil cut out from the base metal of welded joint was prepared. A specimen with a thickness of $1 \mathrm{~mm}$ was mechanically thinned on sand papers down to $0.055 \mathrm{~mm}$, then dimple ground in a diamond suspension. After this operation the thickness of the spherical area was about $0.02 \mathrm{~mm}$. The 
final step of preparation was ion beam polishing. After thinning to electron transparency, TEM observations were made using a JEM-2010 ARP JEOL instrument. Vickers microhardness survey was performed using a Zwick/Roell $\mathrm{ZH} \mu$ testing machine at room temperature with a load of $300 \mathrm{~g}(2.94 \mathrm{~N})$. Time of force loading indenter was 10 seconds and the distance between adjacent indents was $250 \mu \mathrm{m}$. The survey on the welded joint was preceded by measurements on hardness standard test block 278.5 HV0.3. Certified diagonal length for test block is $44.6 \mu \mathrm{m}$ and on the basis of three test measurements an average score of $44.5 \mu \mathrm{m}$ was obtained. Indents were carried out on the weld, heat affected zone (HAZ) and the aged base metal.

\section{RESULTS AND DISCUSSION}

\section{Base metal characterization}

The microstructure of base metal which is shown in Fig. 1 is characteristic for the face centered cubic crystal structure. Nickel alloys solidify as austenite which is stable upon cooling to room temperature. Large equiaxed grains of the matrix as well as twin boundaries are well visible. The grain size of the matrix, quantity and distribution of particles varies. The primary carbides $\mathrm{M}_{6} \mathrm{C}$-type, which are precipitated both within the grains and on grain boundaries during solidification, are certainly present, but evidence of other precipitation cannot be verified using light microscopy [11].

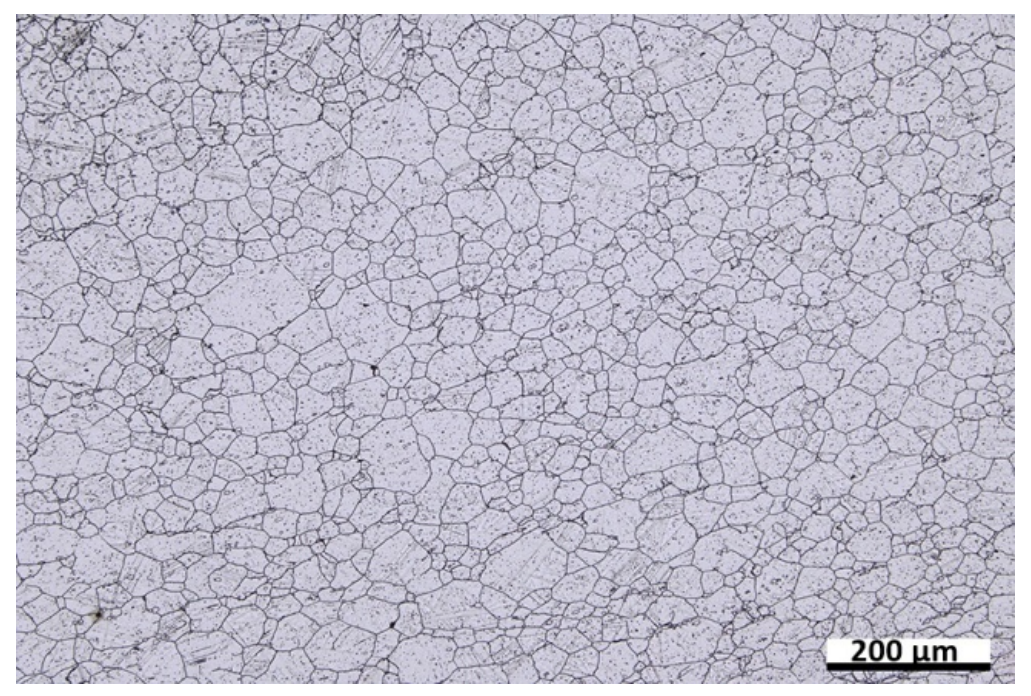

Fig. 1. Microstructure of base metal before the welding process

Information about operating temperature of the turbine part from which the sample was cut was not given. Phases detected by transmission electron microscopy and time-temperaturetransformation diagram of Hastelloy X prepared by Zhao [7] allowed us to initially estimate the operating temperature of the material. The precipitates formed during service conditions are present in Fig. 2. $\mathrm{M}_{6} \mathrm{C}$ carbides only were identified and, despite an intensive investigation, other phases were not detected. it can therefore be assumed that operating temperature did not exceed $500^{\circ} \mathrm{C}[7]$. 


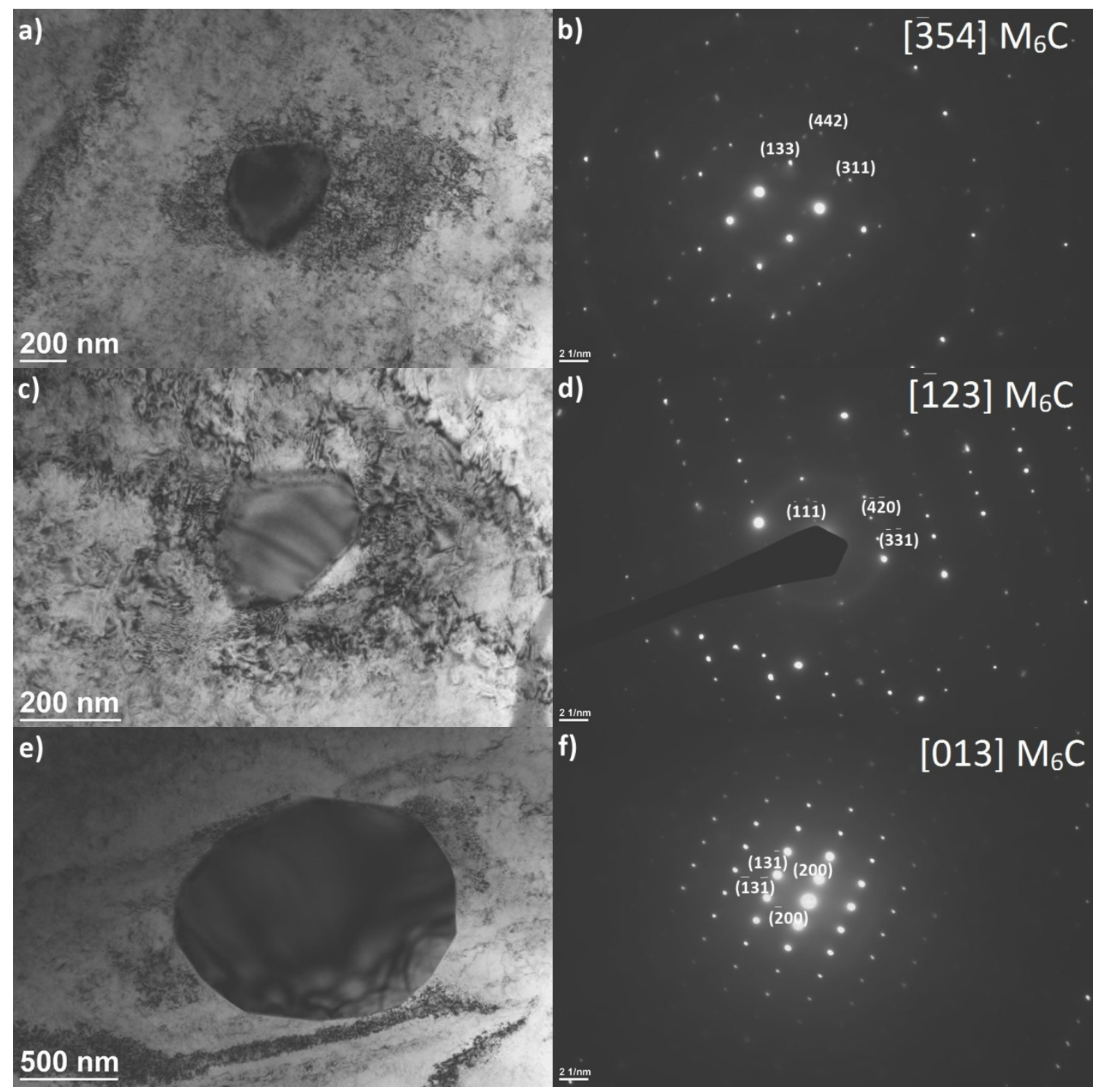

Fig. 2. Transmission electron microscopy bright field images and selected area diffraction patterns

\section{Characterization of welded joint microstructure}

In Fig. 3 weld and heat affected zone is presented. On the basis of the microstructure, it was found that the repair process has been properly made. Welding defects and discontinuities were not detected. Microstructure confirmed correct repair by the selected parameters of the welding process. Despite high density of molten nickel in the weld pool, lack of penetration was not observed. A very narrow mixed zone was observed, which is characteristic for joints which require high corrosion resistance: welding with a low heat input in order to minimize segregation in the fusion line. 


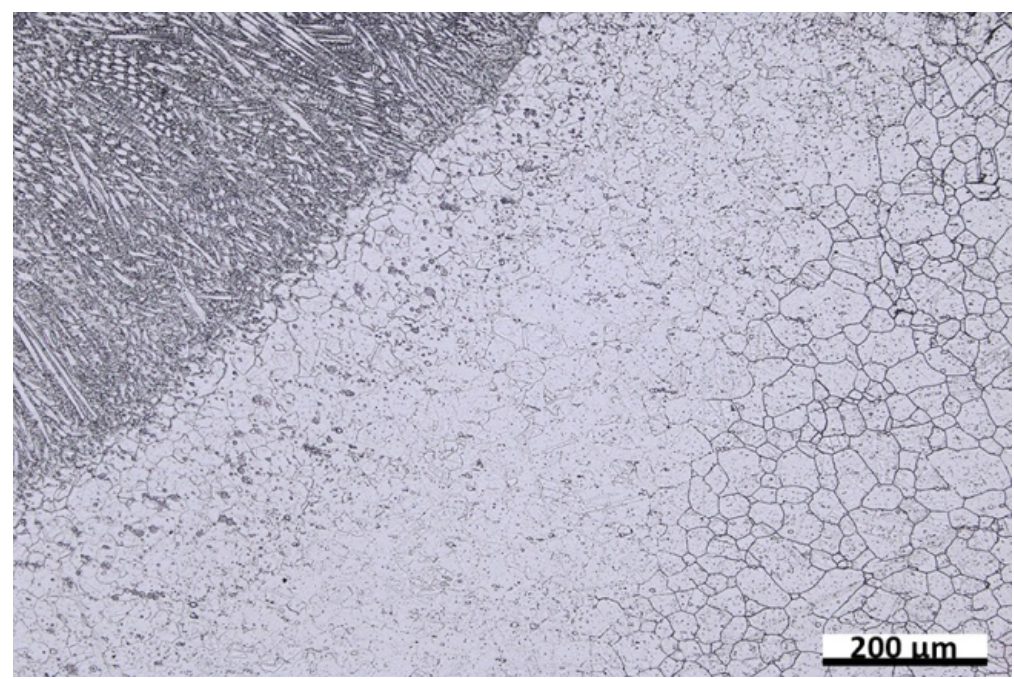

Fig. 3. Microstructure of weld and heat affected zone after repair welding proces

In order to observe more microstructure details, scanning electron microscopy of a characteristic area of welded joint is presented in Fig. 4.

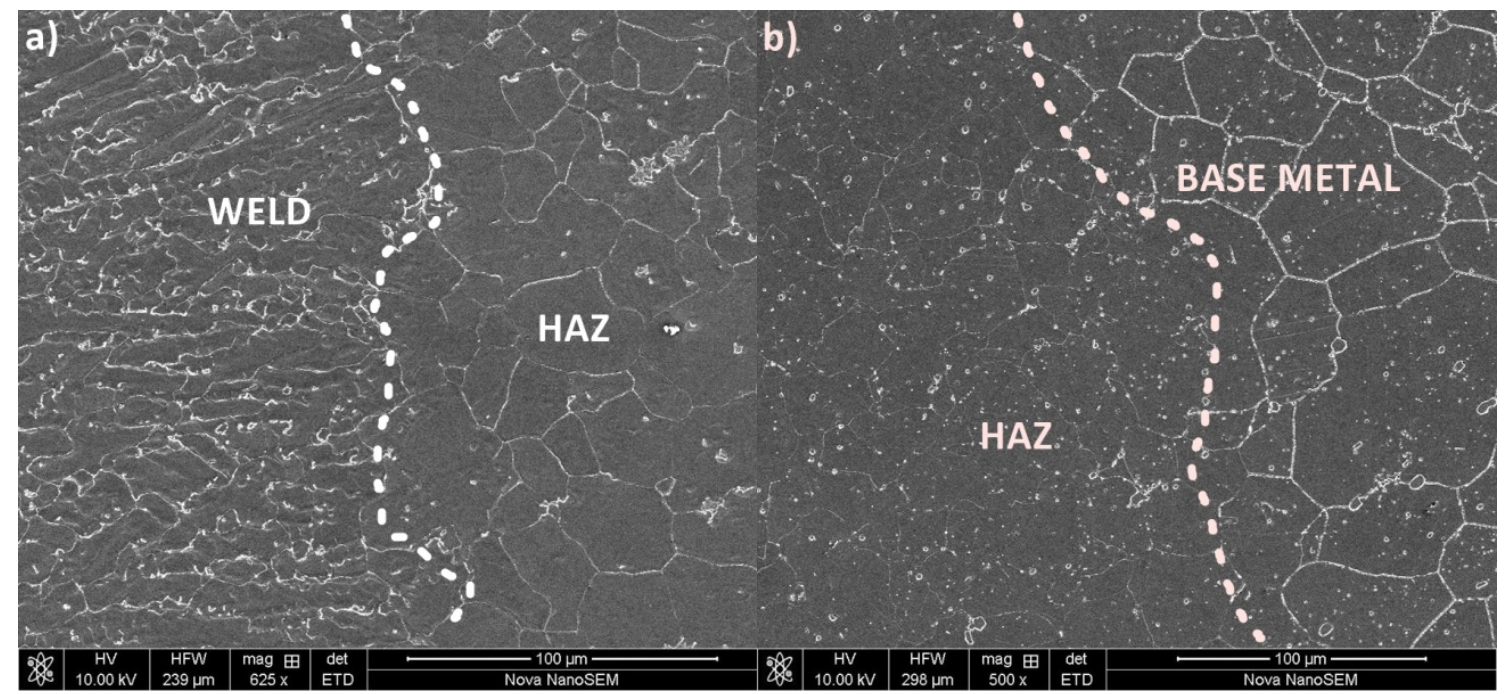

Fig. 4. Scanning electron microstructure of repair weld: a) weld metal and HAZ; b) HAZ and base metal

It should be noted that the thermal cycle in the heat affected zone and the base metal was completely different. Microstructural changes in base metal were connected only with long term service conditions. It is visible that grain growth did occur. Fig. 4 shows a gradual increase in the amount of precipitates from the HAZ in the direction of the base material, with a clear dividing line between those areas. Difference in density of precipitation was induced by the welding process. In the heat affected zone adjacent to the fusion line, heat input caused dissolution of alloying elements, but rapid cooling retained them inside the $\gamma$-matrix. With increasing distance from the fusion line to the base metal, heat input was lower and then the effect of dissolution was less pronounced. Confirmation of the above mentioned opinion was made during the hardness survey.

Fig. 5 is shows the morphology of precipitates both in HAZ and base material. Long term service in industrial conditions caused changes in the base metal microstructure which is visible in the form of large carbides, both within grains and along grain boundaries. In the 
heat affected zone mainly grain boundaries are occupied by particles. Length of these features exceeds even $15 \mu \mathrm{m}$. Comparison of morphologies allows us to state that eutectics formed along grain boundaries in HAZ. The liquated and resolidified material along the grain boundaries consists of $\gamma$ and carbides precipitated during long term service. At the boundaries melting temperature was reduced. The material became a solid and liquid mixture, that is partially melted. These regions with sufficiently high welding stresses can initiate cracking. The level of welding stresses resulting from the single layer joint was too low to initiate cracking [12-14].

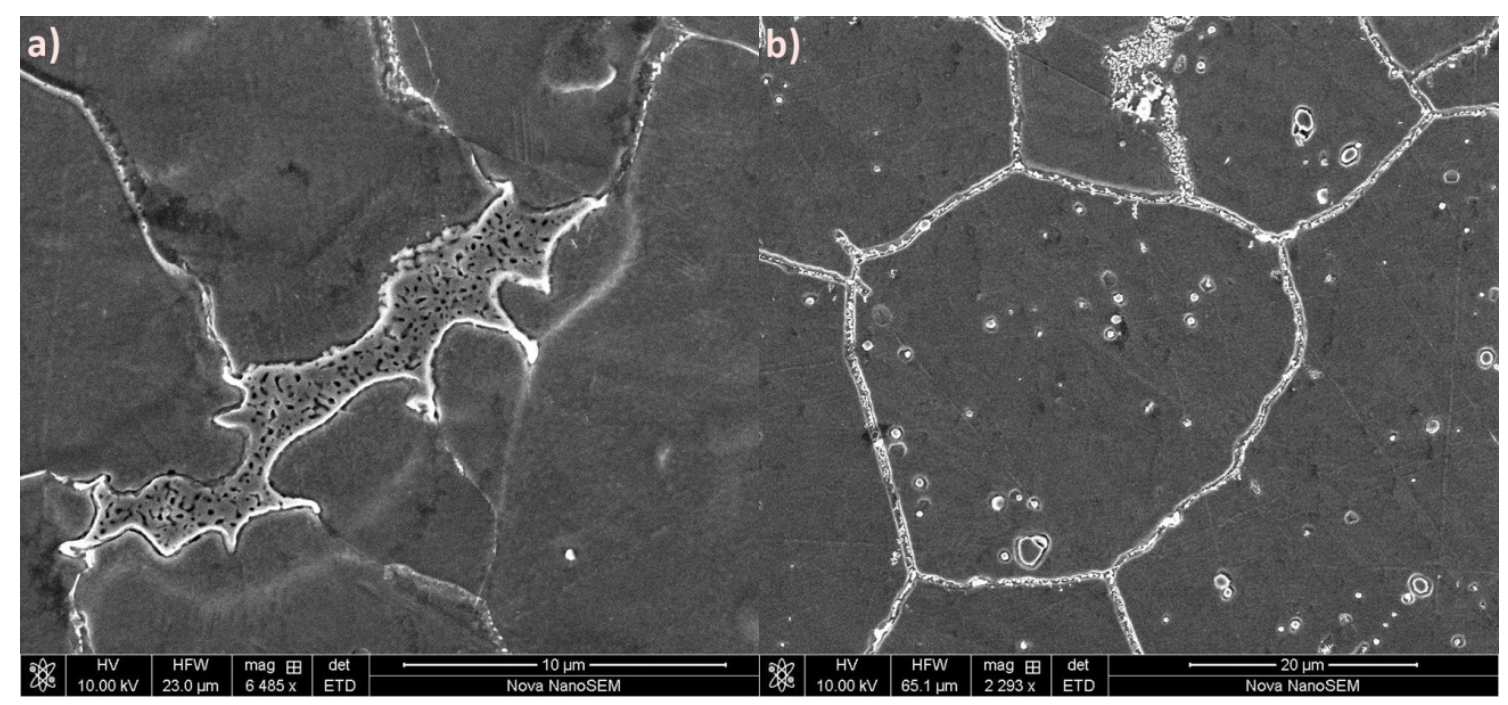

Fig. 5. Precipitations in welded joint: a) eutectic in HAZ; b) carbides in base metal

\section{Energy dispersive spectroscopy of weld}

Welds made of filler metal Hast-X (ERNICrMo-2), the same as the base metal, are composed of the matrix and primary molybdenum rich carbides $\mathrm{M}_{6} \mathrm{C}$-type. In Fig. 6 distribution of elements in the weld is shown and in Fig. 7 EDS spectrum of matrix and $\mathrm{M}_{6} \mathrm{C}$ type carbide.

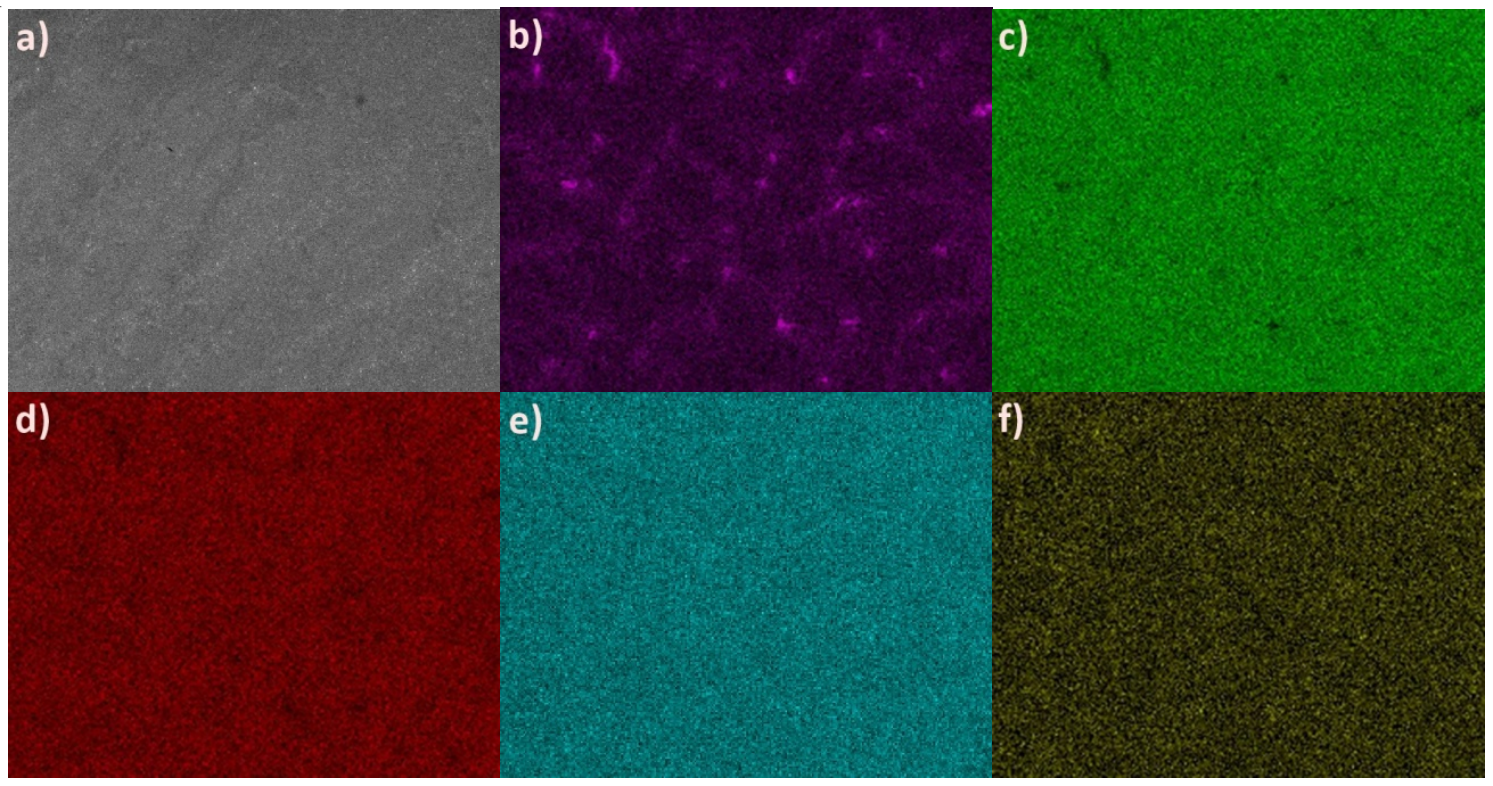

Fig. 6. Map the distribution of elements in the weld (a): b) molybdenum, c) nickel, d) ferrous, e) chromium, f) tungsten. SEM mag. x2000 
a)

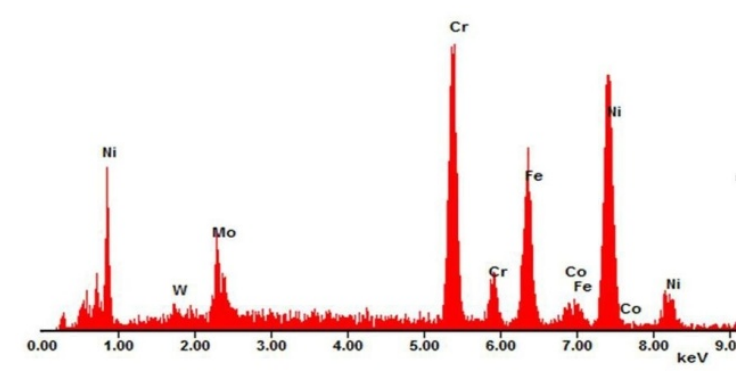

b)

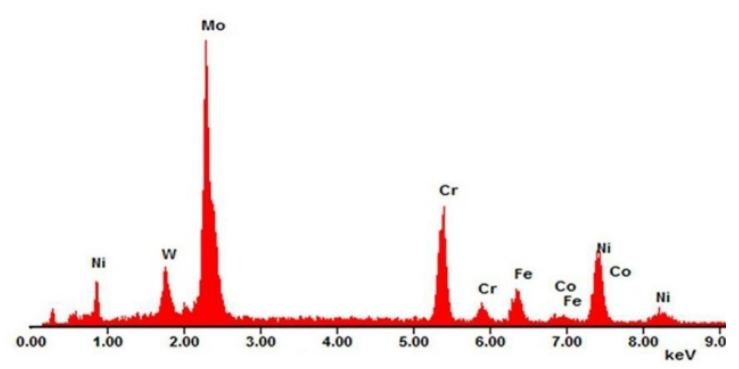

Fig. 7. EDS spectrum: a) matrix; b) M6C-type carbide

Change of colour intensity (Fig. 6) represents enriched and depleted areas of individual elements. The greatest fluctuations were observed for molybdenum, since this is the main element in the carbides. Intensity of colour indicates that they are uniformly distributed in the weld. Enrichment of certain areas in Mo is equivalent to depletion in $\mathrm{Ni}$ and Fe. These elements are not part of the carbides because $\mathrm{Ni}$ is the matrix of the alloy, and task of $\mathrm{Fe}$ is solid solution strengthening. Chromium and tungsten are regularly distributed in the weld. Chromium, as well as tungsten, is in solution, but small amounts of these elements may be included in the $\mathrm{M}_{6} \mathrm{C}$-type carbide.

\section{Microhardness survey of welded joint}

Measurements points were selected to define the hardness of each characteristic area: ie. weld, heat affected zone and base metal. Results are presented in Table 3.

Table 3. Microhardness HVO.3 results

\begin{tabular}{|ccc|}
\hline Weld & Heat affected zone & Base metal \\
\hline 216 & 269 & 253 \\
\hline 226 & 267 & 267 \\
\hline 221 & 246 & 256 \\
\hline 215 & 243 & 261 \\
\hline 215 & 268 \\
\hline \multicolumn{3}{|c|}{ Mean value } \\
\hline 219 & 247 \\
\hline \multicolumn{3}{|c|}{ Standard deviation } \\
\hline 4,8 & 12,9 \\
\hline
\end{tabular}

Analysis of measurements value allows us to say that, the operating temperature during service had significant influence on microhardness of Hastelloy $\mathrm{X}$. The highest values measured in HAZ and base metal confirmed microstructural changes. Values both in HAZ and base metal were quite similar and achieved almost 270 HV0,3. Measurements confirm the conclusion presented in the previous section relating hardness to density of precipitates in HAZ and base metal. The lower hardness were recorded in weld which correspond with Hastelloy $\mathrm{X}$ in virgin condition. 


\section{CONCLUSION}

The aim of this paper was to investigate the microstructure and hardness of Hastelloy $\mathrm{X}$ welded joint after the repair process performed using Gas Tungsten Arc Welding. Microstructural changes resulting from long term service of base metal and welding process are important because of mechanical properties. Presented results confirm that aged base metal did not influence the weldability of Hastelloy X. Despite the presence of eutectic phase in the heat affected zone and continuous carbide layers along grain boundaries, cracking did not occur. Transmission electron micoscopy confirmed that precipitates in the base metal were $\mathrm{M}_{6} \mathrm{C}$-type carbides. Microhardness measurements confirmed microstructural investigation that brittle TCP phases did not exists. Selection of welding parameters confirmed that repair process had been made properly.

\section{ACKNOWLEDGEMENTS}

Łukasz Rakoczy wishes to express appreciation to Professor Stanislaw Dymek (AGH University of Science and Technology in Cracow) for support of the transmission electron microscopy. This research work was supported by the Polish Ministry of Science and Higher Education, Grant No. 11.11.110.299.

\section{REFERENCES}

1. Pollock T. M., Tin S., Nickel-based superalloys for advanced turbine engines: chemistry, microstructure, and properties. Journal of Propulsion And Power, 22, 2 (2006) 361-374.

2. Henderson M.B., Arrell D., Heobel M., Larsson R., Marchant G., Nickel based superalloy welding practices for industrial gas turbine applications. Science and Technology of Welding and Joining, 9, 1 (2004) 13-21.

3. Sridhar S.P., Kumar A., Sathiya P., A Study on effect of different activating flux on A-TIG welding process of Incoloy 800H, Advances in Materials Science, 16, 3 (2016) 26-37.

4. Najafzadegan F., Mansori H., Shamanian M., Investigation of microstructure of the weld zone of Hastelloy X via pulsed Nd-Yag laser welds. Journal of Advanced Materials and Processing, 1, 4 (2013) 49-56.

5. Aghaie-Khafri M., Golarzi N., Forming behavior and workability of HastelloyX superalloy during hot deformation. Materials Science and Engineering A, 486 (2008) 641-647.

6. Wul S-J, Du Ch-W, Kuo Ch-M., Comparison of the Mechanical Properties of Hastelloy X Material after Welding by GTAW and Nd-YAG Laser. Materials Science Forum, 638-642 (2010) 2499-2504.

7. Zhao J.-C., Larsen M., Ravikumar V., Phase precipitation and time-temperature transformation diagram of Hastelloy X. Materials Science and Engineering A293 (2000) 112-119.

8. Clarke W.L. Jr., Titus G.W., Evaluation Study of Hastelloy X as a Nuclear Cladding Oxidation and Structural Stability Investigations, Report c AGN-8289, Vol. 1, Nuclear Division Aerojet General Corporation, San Raman, Ca, 1968. 
9. Baek E.R, Park S.S., Sihotang R., Choi Sang-kyu., Heat treatment of the degraded Hastelloy-X for high cycle fatigue properties, 9th International Conference on Fracture \& Strength of Solids, Jeju, Korea 2013.

10. A5.14/A5.14M:2005 Specification For Nickel And Nickel-Alloy Bare Welding Electrodes And Rods.

11. Tawancy H. M., Long-term ageing characteristics of Hastelloy alloy X. Journal of Materials Science, 18 (1983) 2976-2986.

12. Lippold J. C., Baeslack W. A., Varol I., Heat affected zone liquation cracking in austenitic and duplex stainless steels. Welding Journal 71 (1992) 1-14.

13. Kou S., Solidification and liquation cracking issues in welding. The Journal of The Minerals, Metals \& Materials Society, 55, 6 (2003) 37-42.

14. Rakoczy Ł., Zielińska-Lipiec A., Tuz L., Góral T., Liquation cracking induced by Nd-YAG laser beam in selected nickel based superalloys (in polish). Biuletyn Instytu Spawalnictwa 1 (2017) 3248. 